\title{
CHARACTERIZATION STUDY ON RECYCLED OCEANIC WASTE IN HYBRID CEMENT AMALGAMS
}

DOI:10.36909/jer.ACMM.16313

\author{
Monisha $\mathrm{R}^{1}$, Balasubramanian $\mathrm{M}^{2 \times}$ \\ 1,2* Department of Civil Engineering, SRM Institute of Science and Technology. \\ Corresponding Author Email Id: balamv86@gmail.com
}

\begin{abstract}
This study investigates the recycled wastes and optimizes the raw materials in the performance of cement. The research emphasis on characteristics of oceanic waste calcium and steel manufacturing waste as a cement replacement, and its target is to achieve a green environment to reduce global warming. The hybrid cement periphrastically reduces the raw material usage in the manufacturing of cement. It will improve the calcium silicate hydrates formation in the ideal transition phase of the binder. In this study, Taguchi methods are followed in mix design proportion of cement mortar including water-cement ratio $(0.45,0.5$ and 0.6) and results in the compressive strength in three different ages (7th, 14th and 28th days) were observed. The bulk crystalline constituent patterns are carried out in different magnifications using Scanning Electron Microscope, and its pore structure is studied. The results indicate the composition of pores due to the fineness of hybrid material causes poor flow value. Hence, the use of superplasticizer (SP) to attain the consistency of the mortar to improve the workability and the mechanical properties of the hybrid material composites.
\end{abstract}

Key Words: Waste Management, Recycled waste, Cement Amalgams, SEM analysis and EDS analysis. 


\section{INTRODUCTION}

The demand for conventional building materials has been increasing nowadays and creating high environmental impacts like $\mathrm{CO}_{2}$ emission, minerals endangered, lowering water table levels, lower soil stability etc. So, there is a need for the processing of waste materials into account for using building materials to avoid the scarcity of conventional materials. The production of quick lime $(\mathrm{CaO})$ is by treating the Calcium Carbonate $\left(\mathrm{CaCO}_{3}\right)$ with thermal energy. The resulting $\mathrm{CaO}$ has the potential of binding ability, which can prepare mortars or concretes (Moropoulou A et al. 2001).

The limestone has many applications in various fields like construction, metallurgical, industrials and environmental fields (Cao X et al. 2008), (de Diego LF et al. 2011), (Moon DH et al. 2011), (Mymrin VA et al. 2015) and (Zhang ZS et al. 2015). The industrial usage of limestone is for absorption of $\mathrm{CO}_{2}$ and $\mathrm{SO}_{2}$, which are emitted when the combustion process of fossil fuels. This emission creates many environmental issues like greenhouse gages and acid rainfall. The seizing and holding of carbon have been extensively reviewed to reduce $\mathrm{CO}_{2}$ emission (Stanmore $\mathrm{BR}$ et al. 2005) and (Ma $\mathrm{KW}$ et al. 2009). The carbonation process seizure $\mathrm{CO}_{2}$ from the emission from the materials, and the minerals like calcium, ferrous, magnesium, and silica contents are considered in detail (Gerdemann SJ et al. 2007) and (Sanna A et al. 2014). Resisting the $\mathrm{SO}_{2}$ on the production of Calcium sulphate (leads to Acid rain and smog) when it gets in contact with the atmospheric air by recovering using quick lime (Scala F et al. 2013) and (Gurukumar et al.2021).

The limestone is the raw material in producing the calcium carbonate, which is thermally decomposed to form a quick lime product. The limestone mineral is also one of the natural resources which are obtained from the lime rock. To lower the crushing of limestone rocks, an alternative source for getting limestone properties is seashells and eggshells (Ma KW et al.2009) and (Castilho S et al.2013). These shells can be used as an alternative material for producing quicklime due to their twining chemical properties. The production of quicklime by recycling the shell fish waste is an environmentally friendly material in a sustainable waste management manner. When comparing others, the oyster shell waste is one of the potential shell wastes by having $99 \%$ of calcium, which is the optimum criteria for achieving the quicklime product.

The natural pozzolanic materials are replaced with various ratios for blending the oyster shell powder. The blended cement consists of $70 \%$ of natural pozzolanic and $30 \%$ of 
oyster shell powder which is added in intervals of 2 . The mortar samples are cast with the blended cement, which increases in compressive strength (Fatemeh Soltanzadeh et al. 2018). The oyster shell powder achieves high strength with the minimum quantity of cement addition. This reduces the cost and time for clinkering the ordinary Portland cement production. The fineness of oyster shell powder is one of the significant potentialities for achieving higher density in mortar and concrete. The particle size and fineness are evident by characterization studies like Scanning Electron Microscopy (SEM), Energy Dispersive X-Ray Analysis (EDS) analysis (J. Zhao et al. 2016). This study focuses on replacing ordinary Portland cement with oyster shell powder and ground granulated blast furnace slag in producing hybrid mortar (HM) with varying percentages of replacement.

\section{MATERIALS AND METHODS}

\section{Material Properties}

Oyster shells are waste material which is obtained after the removal of flesh from the shell and thrown off as waste. These shells are then treated with acid and washed to remove scales from its surface. Then it is crushed and made to powder which is less than 90microns sized particles. The chemical composition is compared with the ordinary Portland cement grade 53 and GGBS in Table 1. Among the other materials, oyster shell powder holds a maximum of $95 \%$ of $\mathrm{CaCO}_{3}$ (Monisha et al. 2021). This supports the study for replacing oyster shell powder with cement and GGBS to improve its stability and prepare a hybrid mortar with sustainable material. The fine aggregate is taken for preparing the hybrid mortar is Ennore sand of grade III which has the size of 0.09 to 0.5 mm particles.

Table 1. Chemical properties of cementitious materials

\begin{tabular}{|l|c|c|c|}
\hline $\begin{array}{c}\text { Chemical } \\
\text { Components }\end{array}$ & Cement (\%) & OS (\%) & GGBS (\%) \\
\hline $\mathrm{CaCO}_{3}$ & 65.86 & 95.99 & 44.97 \\
\hline $\mathrm{SiO}_{2}$ & 21.7 & 0.69 & 35.10 \\
\hline $\mathrm{Al}_{2} \mathrm{O}_{3}$ & 5.14 & 0.41 & 11.83 \\
\hline $\mathrm{Fe}_{2} \mathrm{O}_{3}$ & 3.72 &.- & 0.40 \\
\hline $\mathrm{MgO}$ & 0.95 & 0.64 & 5.94 \\
\hline $\mathrm{Na}_{2} \mathrm{O}$ & 0.18 & 0.98 & 0.50 \\
\hline $\mathrm{K}_{2} \mathrm{O}$ & 0.71 & - & 0.66 \\
\hline $\mathrm{SO}_{3}$ & 1.74 & 0.72 & 0.60 \\
\hline
\end{tabular}




\section{Mortar Preparation and Testing}

The hybrid mortar is prepared by using OPC 53 grade, oyster shell and GGBS with varying percentages which is clearly shown in Table 2. Four different mix proportions were compared with the conventional cement mortars $(\mathrm{CM})$. There is an issue in flowability property for hybrid mortar in nominal water cement ratio, due to finer particles in oyster shell powder. So, to overcome the issue a super plasticizer was introduced for high range water reducing in preparation of hybrid mortar. The mortar mix is prepared by 1:4 ratio which is composed of 1 part of cement and 4 parts of fine aggregate. Flowability test were carried out for obtaining the optimum water binder ratio. The mixes are made using Digi - mortar mixer and cubes were casted in steel mould of dimension 50mm x 50mm x 50mm Figure 1. According to IS- 4031 (part-6), the mortar cubes were casted and tested using the compression testing machine as shown in Figure 2. A uniaxial load is applied to the mortar cube specimen. The compressive strength test is made for the specimens at different curing days like 7, 14, and 28 days. (M S Guru Kumar et al. 2020) and (S Dinesh et al. 2020).

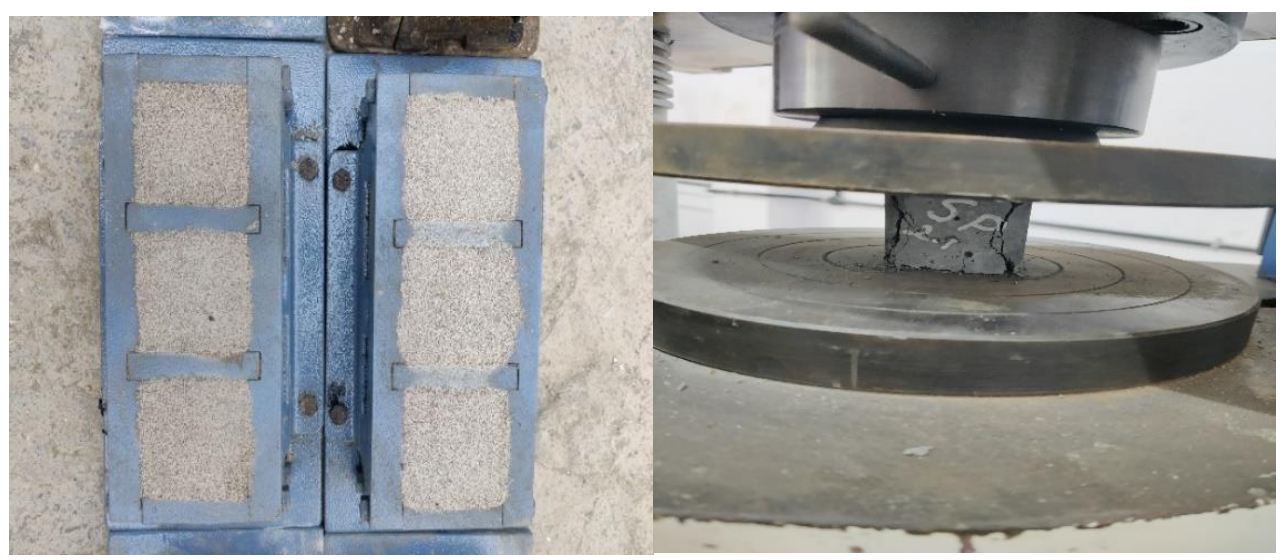

Figure 1. Hybrid mortar

Figure 2. Testing of Cube 
Table 2. Mix Proportions and Quantities

\begin{tabular}{|l|c|c|c|c|c|c|c|}
\hline $\begin{array}{c}\text { Specimen } \\
\text { Id }\end{array}$ & Specimen Name & $\begin{array}{c}\text { w/c } \\
\text { ratio }\end{array}$ & $\begin{array}{c}\text { Cement } \\
(\mathbf{g})\end{array}$ & $\begin{array}{c}\text { OS } \\
(\mathbf{g})\end{array}$ & $\begin{array}{c}\text { GGBS } \\
(\mathbf{g})\end{array}$ & $\begin{array}{c}\text { Sand } \\
(\mathbf{g})\end{array}$ & $\begin{array}{c}\text { Water } \\
(\mathbf{m l})\end{array}$ \\
\hline CM & $\begin{array}{c}\text { C100:OS00: } \\
\text { GGBS00 }\end{array}$ & 0.6 & 58 & 0 & 0 & 229 & 35 \\
\hline HM1 & C50:OS40: GGBS10 & 0.6 & 29 & 23.2 & 5.8 & 229 & 35 \\
\hline HM2 & C50:OS30: GGBS20 & 0.6 & 29 & 17.4 & 11.6 & 229 & 35 \\
\hline HM3 & C50:OS20: GGBS30 & 0.6 & 29 & 17.4 & 11.6 & 229 & 35 \\
\hline HM4 & C50:OS10: GGBS40 & 0.6 & 29 & 5.8 & 23.2 & 229 & 35 \\
\hline HMSP1 & C50:OS40: GGBS10 & 0.45 & 29 & 23.2 & 5.8 & 229 & 26 \\
\hline HMSP2 & C50:OS30: GGBS20 & 0.45 & 29 & 17.4 & 11.6 & 229 & 26 \\
\hline HMSP3 & C50:OS20: GGBS30 & 0.45 & 29 & 17.4 & 11.6 & 229 & 26 \\
\hline HMSP4 & C50:OS10: GGBS40 & 0.45 & 29 & 5.8 & 23.2 & 229 & 26 \\
\hline
\end{tabular}

\section{Characterization Study}

The particle size of materials and its combinations were studied in detail by using Scanning Electron Microscopy and Energy Dispersive X-Ray Spectroscopy. The pore structure, size and shape of the micro particles are analysed. The particle's surface decides the binding ability of the material which is clearly evident in SEM imaging. The material taken for study should also be studied for the composition formed when it is bonded with water and other materials. This issue has been recovered by EDS analysis which shows the composition of the material reacted.

\section{RESULT ANALYSIS}

\section{Flowability Test}

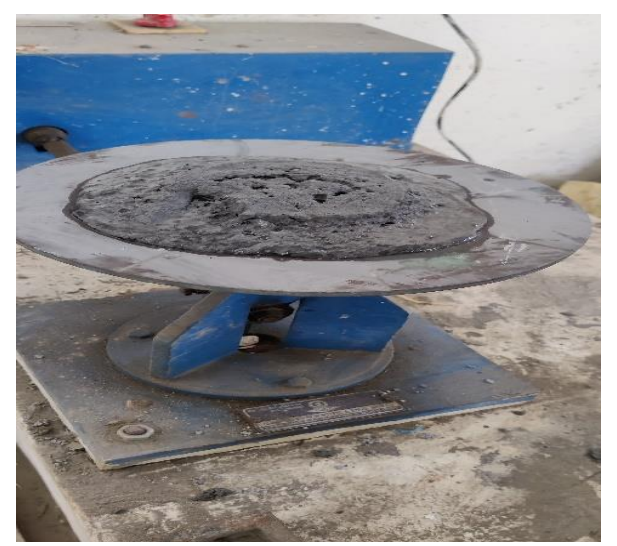

Figure 3. Flow Table Test

The flowability of mortar is the basic property in which mortar should possess in fixing the optimum water binder ratio. Flow table test for mortar is made for various mortar mixes 
which composed of cement, oyster shell and GGBS. As per the codal provision (ASTM C230-14), the flowability of blended mortars was tested Figure 3. Initially, conventional cement mortar attains the flowability in 0.4 to 0.45 water cement ratio. But, in this study, the fine aggregate used is grade III Ennore sand which is finer than the conventional sand. So, the water binder ratio for conventional mortar attains its flow around 0.55 to 0.6 . The oyster shell powder is finer than OPC. This influence the reduction in flowability of mortar and to recover this more water is required. To overcome the addition of excess water to satisfy the flowability, a high range water reducing agent is introduced in the mortar preparation. After using a superplasticizer, the water binder ratio is lowered without compromising the flowability of the mortar sample which shows in Table 3.

Table 3. Flow Table Test

\begin{tabular}{|c|c|c|c|c|c|c|c|c|c|c|}
\hline Description & \multicolumn{5}{|c|}{ Flowability (Without SP) $0.6 \%$} & \multicolumn{5}{|c|}{ Flowability (With SP) $0.45 \%$} \\
\hline Specimen & $\mathrm{C}$ & HM & $\mathrm{HM}$ & HM & HM & $\mathrm{C}$ & HMSP & HMSP & HMSP & HMSP \\
\hline Code & M & 1 & 2 & 3 & 4 & M & 1 & 2 & 3 & 4 \\
\hline $\begin{array}{c}\text { Flowability } \\
(\%)\end{array}$ & 75 & 53 & 57 & 69 & 72 & 75 & 58 & 64 & 70 & 74 \\
\hline
\end{tabular}

\section{Compressive Strength Test}

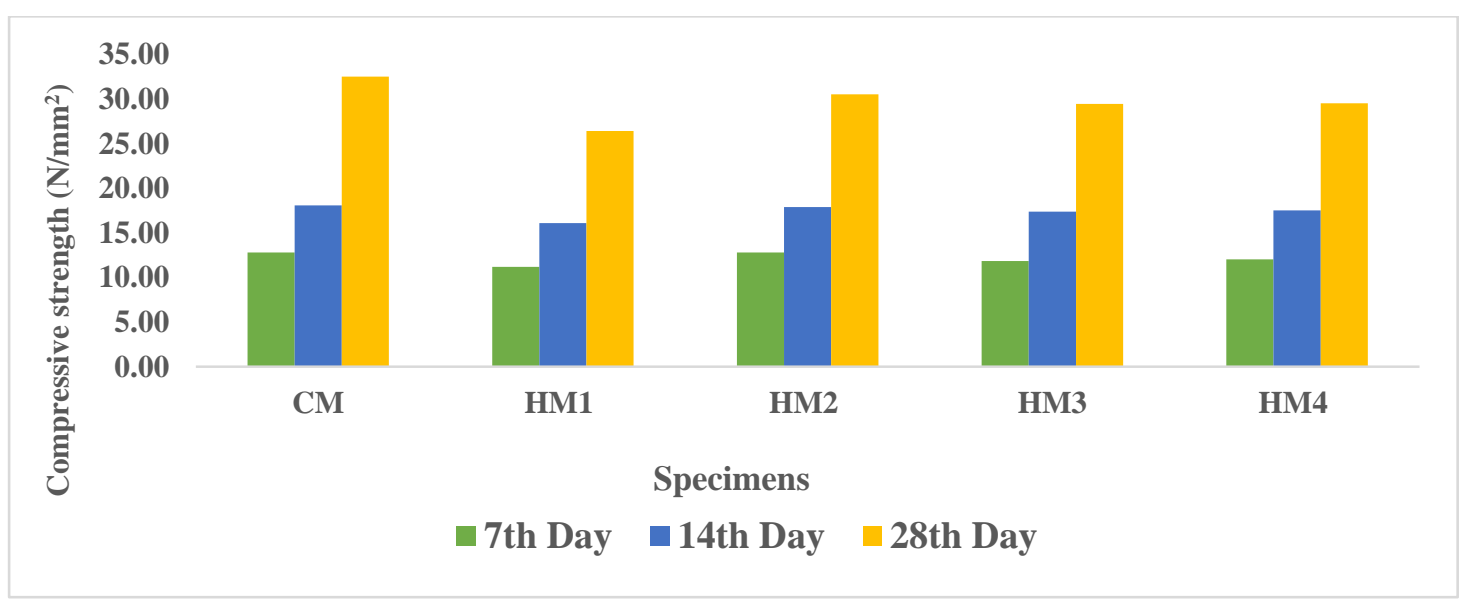

Figure 4. Compressive Strength (Without SP)

The compressive strength for $50 \mathrm{~mm}$ cube has been tested and calculated as per IS 2250 (1981). Figure 4. Shows the compressive strength test results for 7, 14, 28 curing days of mortar specimen in various proportions. The hybrid mortar of 4 proportions is compared with the conventional cement mortar. Comparing all the specimen's conventional mortars achieves the higher strength. But, when comparing the outcomes, the HM2 proportion attains more strength than other hybrid mortars. This satisfies the target strength that is designed as 
per the codal provisions. These results achieved the strength but the flowability has to be taken care off. The increase in the addition of water to the mortar mix will improve the flowability, thinking on the other hand the strength will directly decrease. To avoid the circumstance a high range water reducing superplasticizer has been input to resolve the issue. The strength and flowability are improved that is evident in Figure 5.

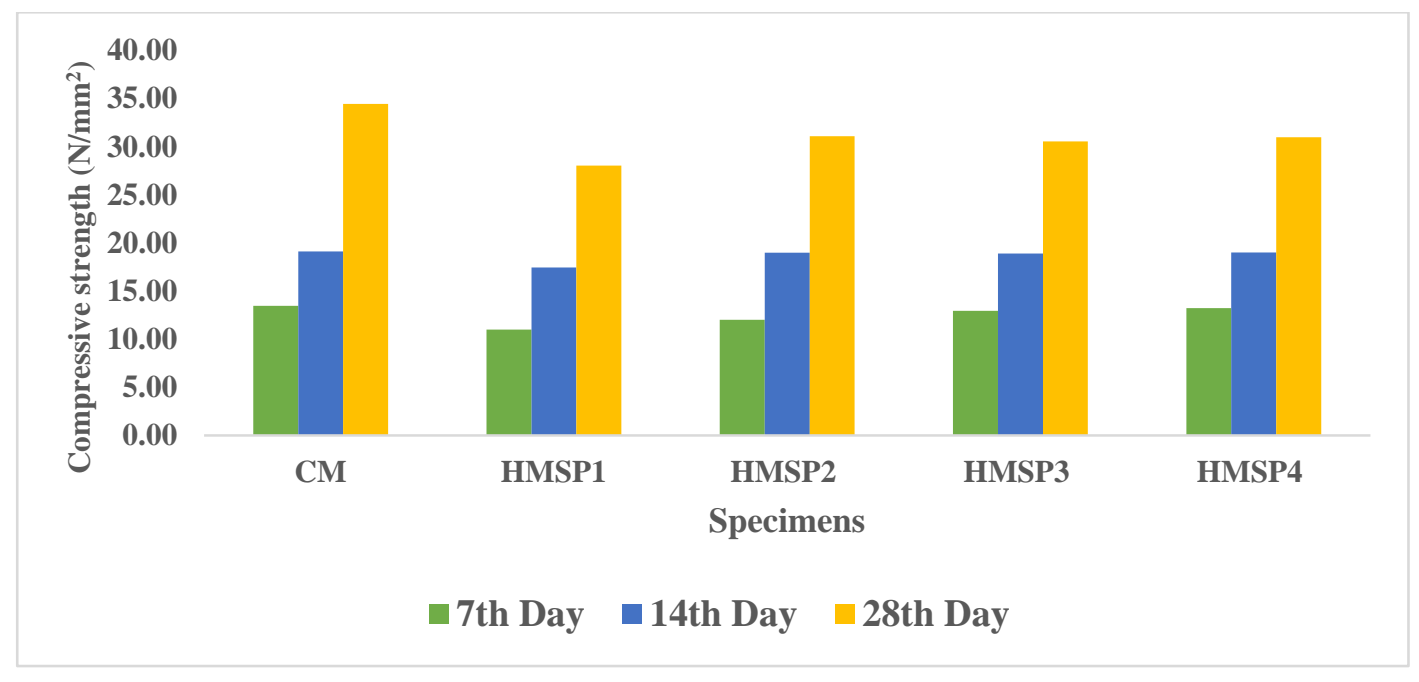

Figure 5. Compressive Strength (With SP)

\section{SEM Analysis}

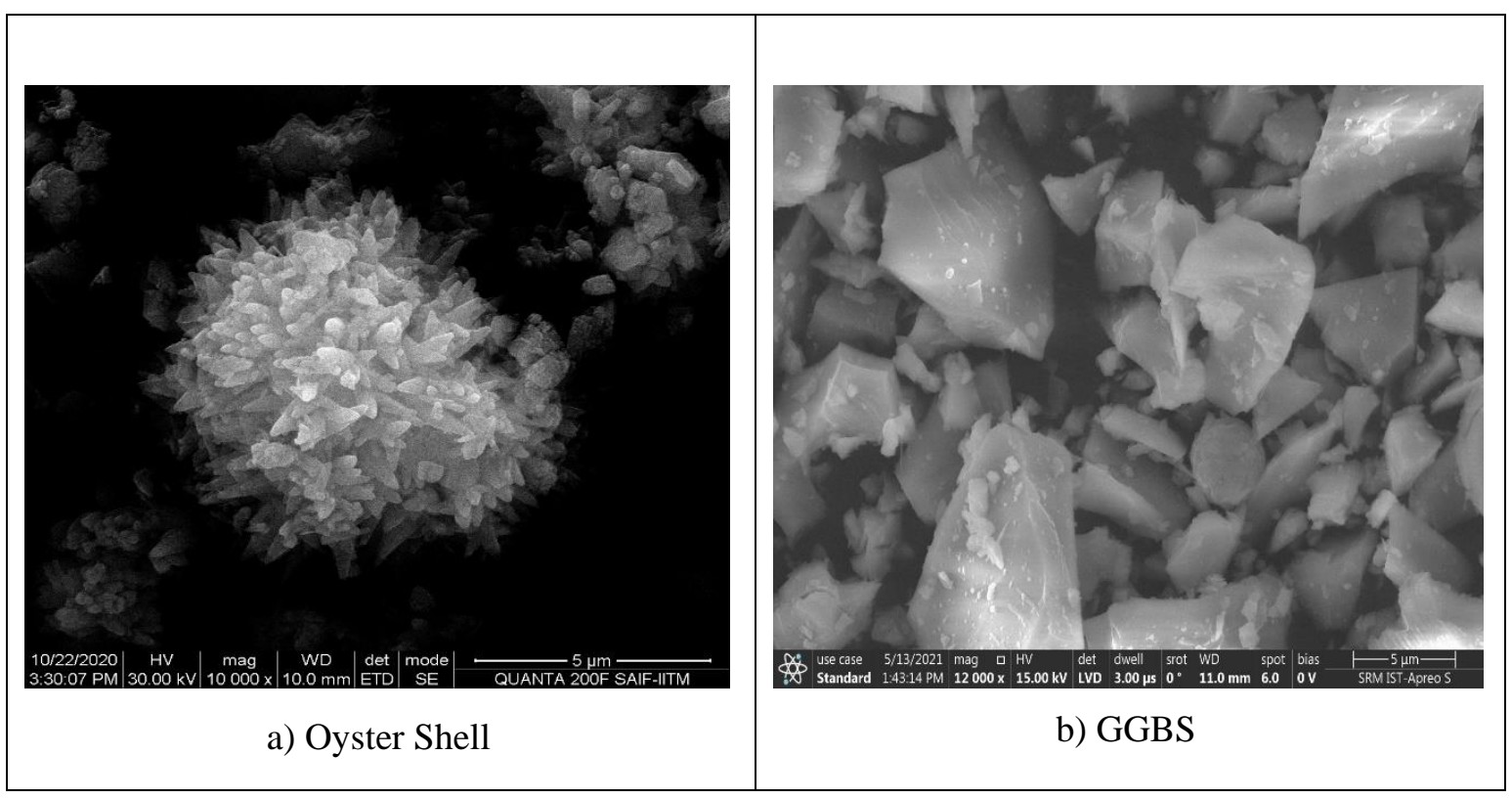




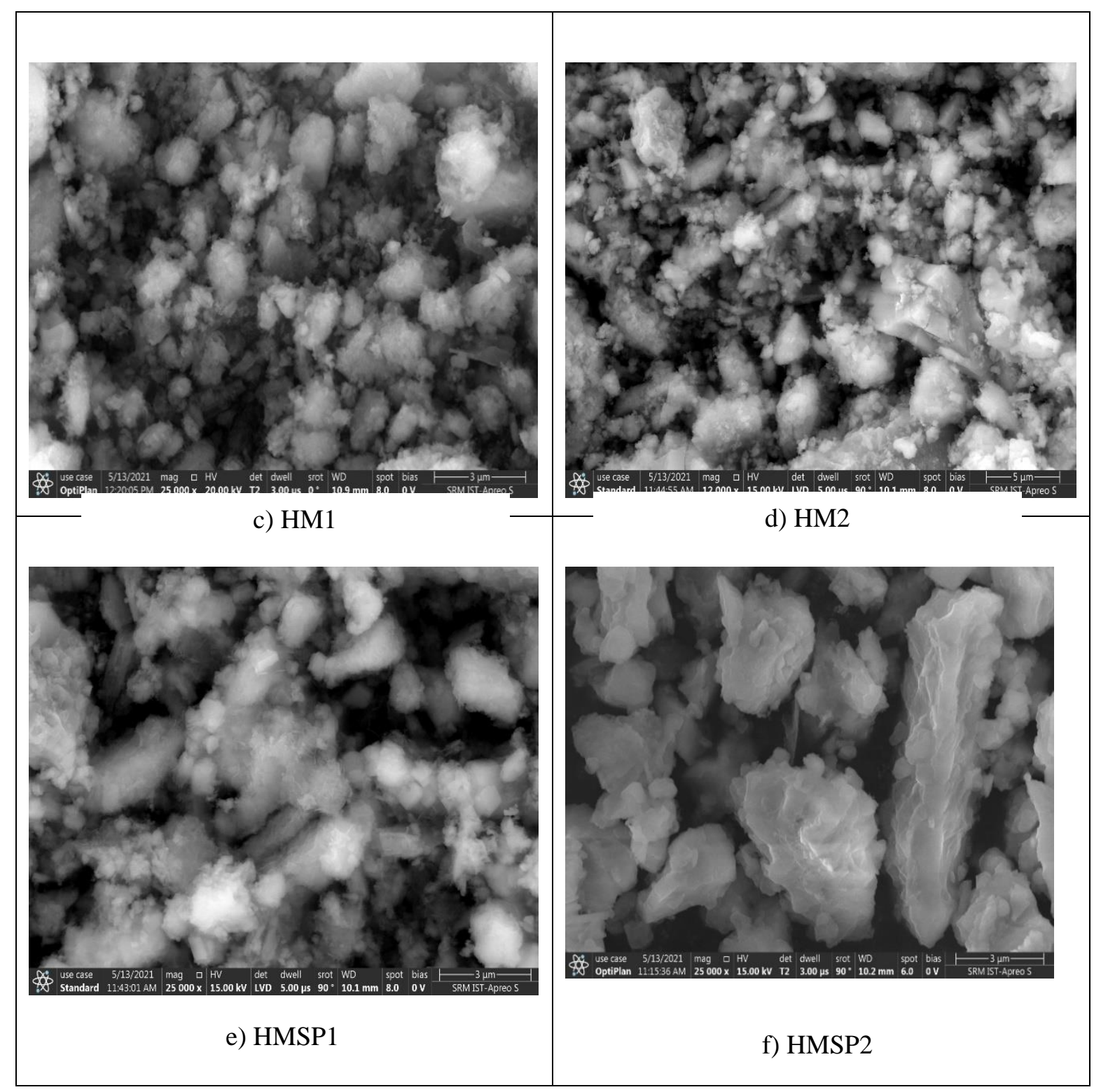

Figure 6. SEM Imaging

The microstructural analysis was made by many researchers in finding the evidence for the increase and decrease in strength by its shape and size effects. The scanning electron microscopy test is conducted for oyster shell and GGBS material, then for the mortar samples (HM1, HM2, HMSP1 \& HMSP2). The black and white spotted in images are un-hydrated and hydrated compounds that decide the strength factors. Comparing the images of materials, the oyster shell powder shows a denser surface due to being finer in size when compared to the GGBS. The GGBS material also proves the crystalline structures and irregularity in shapes but pores are high. The mortar combination is compared for two mix combinations with and without superplasticizers (HM1, HM2 and HMSP1, HMSP2). 


\section{EDS Analysis}

The Energy Dispersive X- Ray Spectroscopy analysis is to study the chemical composition of the materials and for mortar combinations. The comparison is made for oyster shell and GGBS material in which the calcium and silica decide the strength of the material in forming $\mathrm{C}-\mathrm{S}-\mathrm{H}$ gel when reacted with water. The oyster shell holds the maximum percentage of calcium and GGBS has both silica and calcium which compose more C-S-H gel. The optimum percentage of hybrid mortar is taken for this EDS analysis for both with SP and without SP figure 7. The results show not much variation for with SP and without SP. This shows there is no influence of superplasticizer in changing the chemical composition. It changes the pore structure and forms more crystalline shapes that improve the strength of the mortar.

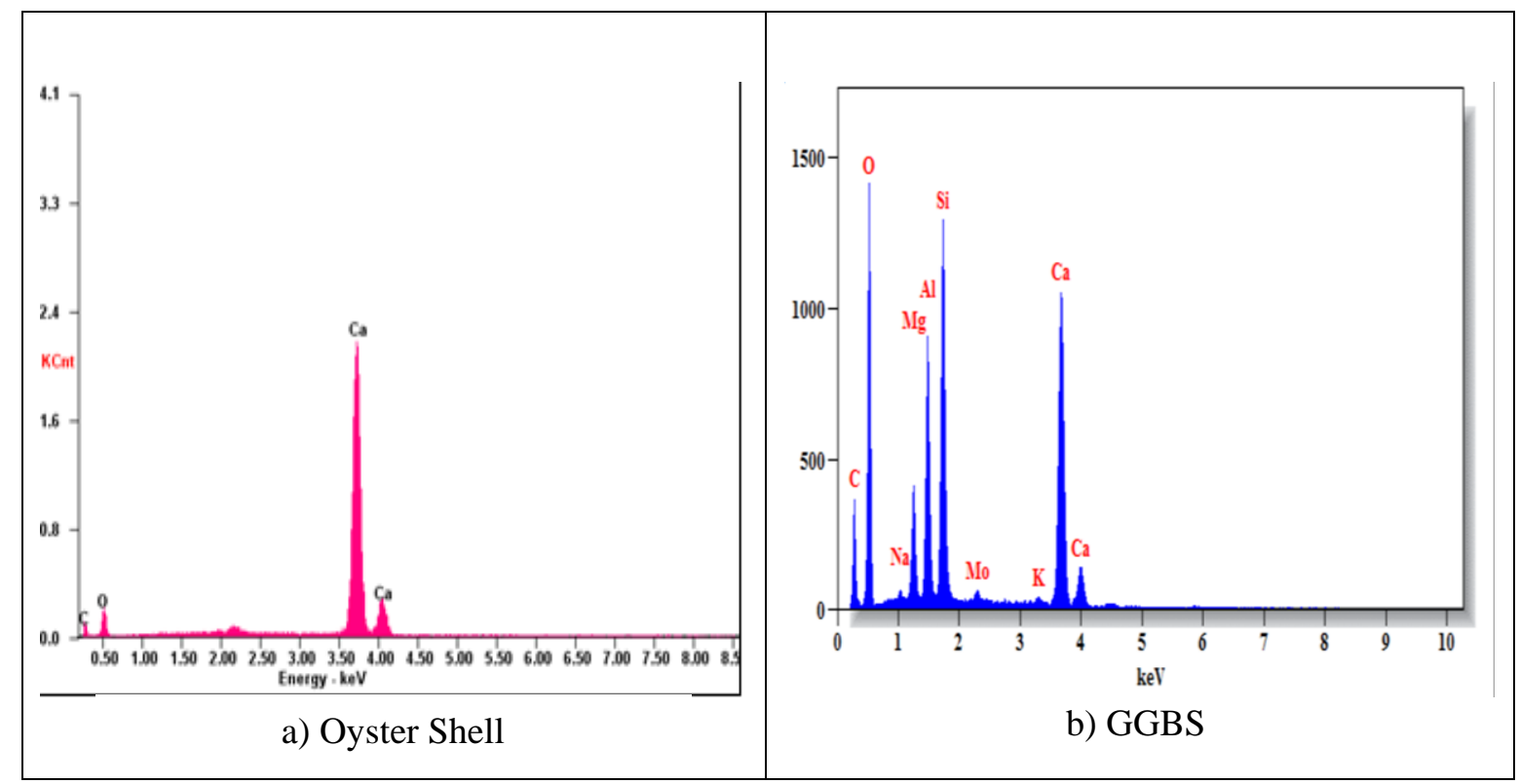




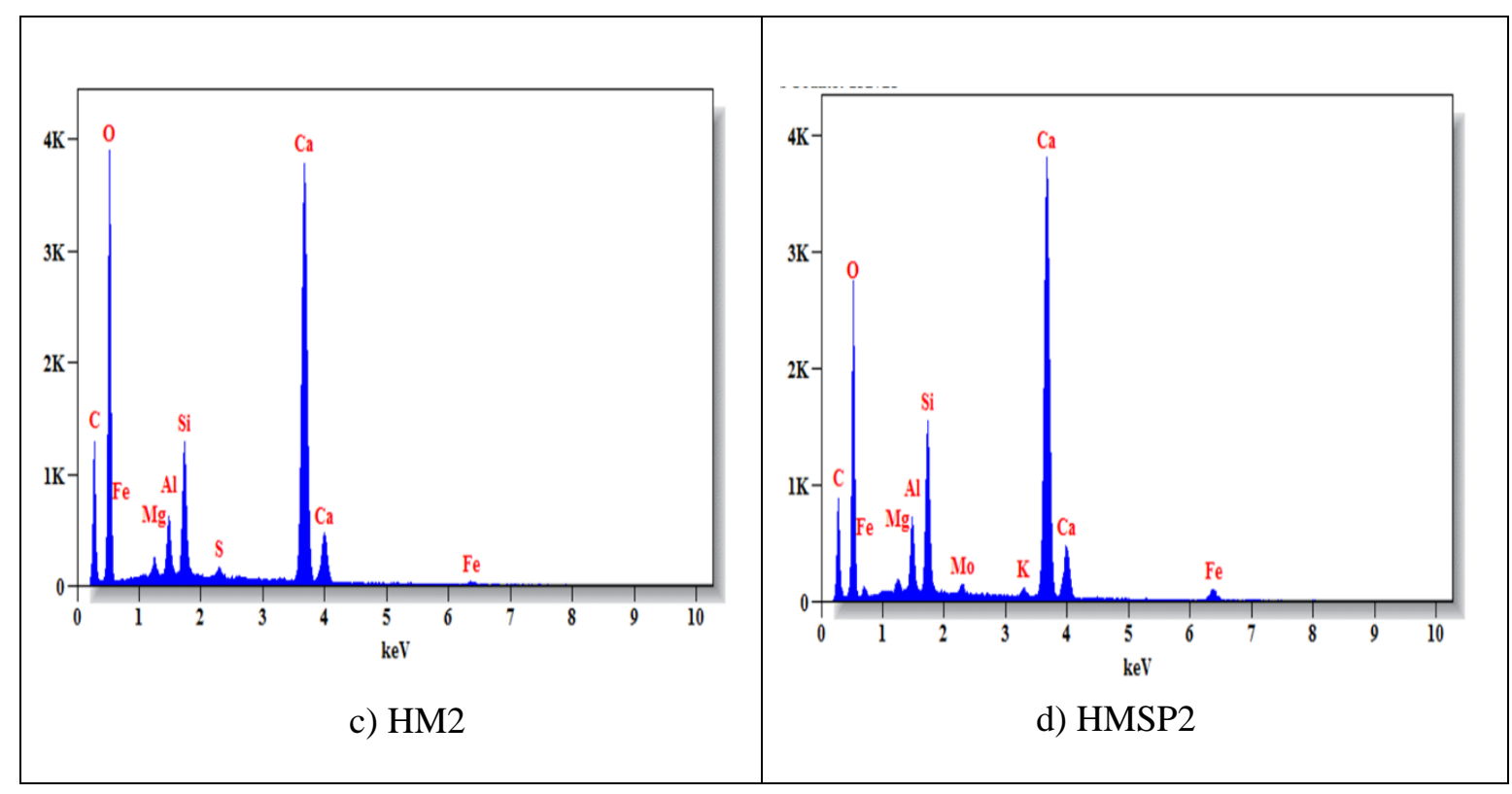

Figure 7. EDS Analysis

\section{CONCLUSION}

The behaviour of hybrid mortars is studied in detail with the mechanical property and justified using characterization study. The material hybridization is optimized by Taguchi concepts and the various combinations are tested with compressive strength test.

- The flowability study is made for all the combinations and the results shows poor workability. To overcome, a high range water reducing agent has been used to achieve the desired workability without compromising the strength of the mortar mix.

- On observing the compressive strength of the mortar cubes at 7, 14, and 28 days of curing is studied in detail with all the mix combinations. Comparing all the specimen's conventional mortars achieves the higher strength. But, when comparing the outcomes, HM2 and HMSP2 (C50: OS30: GGBS20) proportion attains more strength than other hybrid mortars. This satisfies the target strength that are designed as per the codal provisions.

- The black and white spotted in images are un-hydrated and hydrated compounds which decides the strength factors. Comparing the images of materials, the oyster shell powder shows the denser surface due to finer in size when compared to the GGBS. The GGBS material is also proves the crystalline structures and irregularity in shapes but pores are high. 
- Figure 6. c \& d shows that increase in water content will improves the pore structure and decrease the density of the specimen, were as Figure 6 . e \& $\mathrm{f}$ shows the crystalline formation due to its proper addition of water using super plasticizer improves the density of the mortar.

- The comparison is made for oyster shell and GGBS material in which the calcium and silica decides the strength of the material in forming C-S-H gel when reacted with water. The oyster shell holds the maximum percentage of calcium and GGBS holds both silica and calcium which compose more C-S-H gel. 


\section{REFERENCES}

Moropoulou A, Bakolas A, Aggelakopoulou E (2001). The effects of limestone characteristics and calcination temperature to the reactivity of the quicklime. Cem Concr Res 31:633-639.

Cao X, Dermatas D, Xu X, Shen G (2008) Immobilization of lead in shooting range soils by means of cement, quicklime, and phosphate amendments. Environ Sci Pollut R 15:120 127.

Diego LF, de las Obras-Loscertales M, García-Labiano F, Rufas A, Rufas A, Abad A, Gayán P, Adánez J (2011) Characterization of a limestone in a batch fluidized bed Reactor for sulfur retention under oxy-fuel operating conditions. Int J Greenh Gas Con 5:1190-1198.

Moon DH, Kim KW, Yoon IH, Grubb DG, Shin DY, Cheong KH, Choi HI, Ok YS, Park JH (2011) Stabilization of arsenic-contaminated mine tailings using natural and calcined oyster shells. Environ Earth Sci 64:597-605.

Mymrin VA, Alekseev KP, Catai RE, Izzo RLS, Rose JL, Nagalli A, Romano CA (2015) Construction material from construction and demolition debris and lime production wastes. Constr Build Mater 79:207-213.

Zhang ZS, Lian F, Ma LJ, Jiang YS (2015) Effects of quicklime and iron tailings as modifier

on composition and properties of steel slag. J Iron Steel Res Int 22:15-20.

Stanmore BR, Gilot P (2005) Review-calcination and carbonation of limestone during thermal cycling for CO2 sequestration. Fuel Process Technol 86:1707-1743.

Ma KW, Teng $\mathbf{H}$ (2009) $\mathrm{CaO}$ powders from oyster shells for efficient $\mathrm{CO} 2$ capture in multiple carbonation cycles. J Am Ceram Soc 93:221-227.

Gerdemann SJ, O'connor WK, Dahlin DC, Penner LR, Rush H (2007) Ex situ aqueous mineral carbonation. Environ Sci Technol 41:2587-2593.

Sanna A, Uibu M, Caramanna G, Kuusik R, Maroto-Valer MM (2014) A review of mineral carbonation technologies to sequester CO2. Chem Soc Rev 43:8049-8080.

Scala F, Chirone R, Meloni P, Carcangju G, Manca M, Mulas G, Mulas A (2013) Fluidized 
bed desulfurization using lime obtained after slow calcination of limestone articles. Fuel 114:99-105.

Castilho S, Kiennemann A, Pereira MFC, Dias APS (2013) Sorbent for CO 2 capture from biogenesis calcium wastes. Chem Eng J 226:146-153.

Fatemeh Soltanzadeh, Mojtaba Emam-Jomeh, Ali Edalat-Behbahani, Zahra Soltan-

Zadeh, "Development and characterization of blended cements containing seashell powder" Construction and Building Materials 161 (2018) 292-304.

J. Zhao, D. Wang, P. Yan, S. Zhao, D. Zhang, Particle characteristics and hydration activity

of ground granulated blast furnace slag powder containing industrial crude glycerol-based grinding aids, Constr. Build. Mater. 104 (2016) 134-141, https://doi.org/10.1016/j.conbuildmat.2015.12.043.

IS 2250 (1981): Code of Practice for Preparation and Use of Masonry Mortars.

Monisha R, Balasubramanian M, Arul J, Kiranmayi R. 2021, A review on utilizing the marine biorefinery waste in Construction raw materials to reduce land Pollution and enhance green environment, advances in materials science, Vol. 21, No. 3 (69).

Guru Kumar, M. Balasubramanian \& Arul JeyaKumar 2021, A Review on the Mechanical

Properties of Natural Fiber Reinforced Compressed Earth Blocks, JOURNAL OF NATURAL FIBERS. https://doi.org/10.1080/15440478.2021.1958405.

M S Guru Kumar., M. Balasubramanian,” Application of FGC Blocks for Sustainable Infrastructure Development 2020 IOP Conf. Ser.: Mater. Sci. Eng. 912062057.

S Dinesh Kumar Raju., M. Balasubramanian,” Experimental studies On Replacement of Steel Stirrups by Sisal Fiber Reinforced Polymers 2020 IOP Conf. Ser.: Mater. Sci. Eng. 912

062058. 